\title{
Principles and Applications of Fat Grafting in Plastic Surgery
}

\author{
Amjed Abu-Ghname, MD ${ }^{1}$ Aurelia Trisliana Perdanasari, MD ${ }^{1} \quad$ Edward M. Reece, MD, MBA ${ }^{1}$ \\ ${ }^{1}$ Division of Plastic Surgery, Michael E. DeBakey Department of \\ Surgery, Baylor College of Medicine, Houston, Texas \\ Address for correspondence Edward M. Reece, MD, MBA, Jamail \\ Specialty Care Center, 1977 Butler Blvd., Suite E6.100, Houston, \\ TX 77030 (e-mail: edward.reece@bcm.edu).
} Semin Plast Surg 2019;33:147-154.

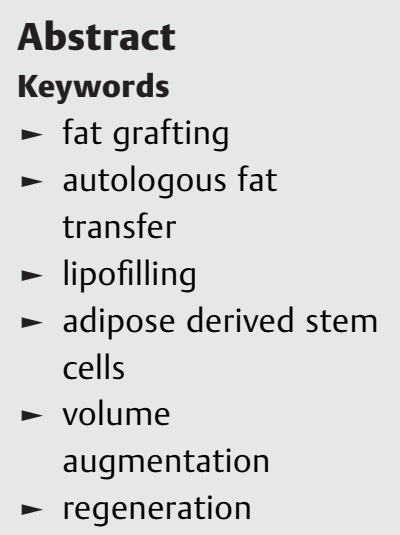

Autologous fat transplantation has become increasingly popular in recent years. Its biocompatable properties and availability made it a widely used treatment modality for soft tissue augmentation and volume replacement in both reconstructive and aesthetic plastic surgery. Multiple protocols and clinical applications have been described in the literature, with wide variations in the harvesting, processing, and injection techniques. In this review, the authors will discuss the basic principles and clinical applications of fat grafting in plastic and reconstructive surgery. The article will then conclude with a discussion of fat grafting limitations as well as potential future applications, giving the reader a well-rounded understanding of autologous fat transfer.
Records of adipose tissue transfer have been described for decades dating back to 1893 when Neuber performed the first autologous adipose tissue transfer to a facial depression scar. ${ }^{1}$ However, it was not until the year 1997 that it gained massive popularity when Coleman described a new advanced technique of fat harvesting that substantially diminished complications and improved graft survival. ${ }^{2}$ Since then, the number of clinical applications for fat grafting has been growing exponentially not only for volume replacement, but also for tissue quality improvement. ${ }^{3}$

Fat is a readily available tissue that does not trigger an immune response or cause significant donor site morbidity when harvested. ${ }^{4}$ Autologous fat grafts are currently being used in a wide variety of procedures in both reconstructive and aesthetic plastic surgery. Some of the prominent applications include primary breast augmentation, breast recontouring, rhinoplasty, facial and hand rejuvenation, and scars treatment. ${ }^{3,5-11}$ In addition, reports of its use in correcting deformities such as Parry-Romberg syndrome, Poland syndrome, and Dupuytren's contracture have been described. ${ }^{12-15}$

Despite its widespread use, one of the main dilemmas when grafting fat tissue is the unpredictable resorption, both in location and extent, resulting in the need for multiple injections, and in some cases poor aesthetic outcome. ${ }^{16,17}$
Harvested adipose tissue is composed of mature adipocytes, extracellular matrix, and a stromal vascular fraction (SVF) that is constituted by several types of cells including adiposederived stem cells (ADSCs). ${ }^{18,19}$ Although remains an area of debate, ADSC-enriched grafts have been associated with better graft viability and outcome after transplantation. ${ }^{19-21}$ Furthermore, different harvesting techniques can result in different outcomes in regards to fat graft take. ${ }^{16}$ Therefore, establishing best-practice guidelines for fat grafting methodology is of utmost importance moving forward to minimize fat graft loss.

\section{Principles of Fat Grafting}

For many decades, fat was considered an inert source of energy. However, studies have demonstrated that adipose tissue has the potential for proliferation and regeneration. Almost $50 \%$ of the in vivo adipose tissue cells consists of ADSCs, in addition to fibroblasts, endothelial cells, and pericytes. ${ }^{22}$ Those ADSCs are multipotent stem cells that have the potential for both proliferation and differentiation. ${ }^{23}$ This regenerative potential has been demonstrated in several clinical studies involving angiogenesis, peripheral nerve regeneration, scarring, and osteoarthritis. ${ }^{24-30}$
Issue Theme Biologics in Plastic Surgery; Guest Editor: Edward M. Reece, MD, MBA
Copyright (C) 2019 by Thieme Medical Publishers, Inc., 333 Seventh Avenue, New York, NY 10001, USA. Tel: +1(212) 584-4662.
DOI https://doi.org/ 10.1055/s-0039-1693438. ISSN $1535-2188$. 


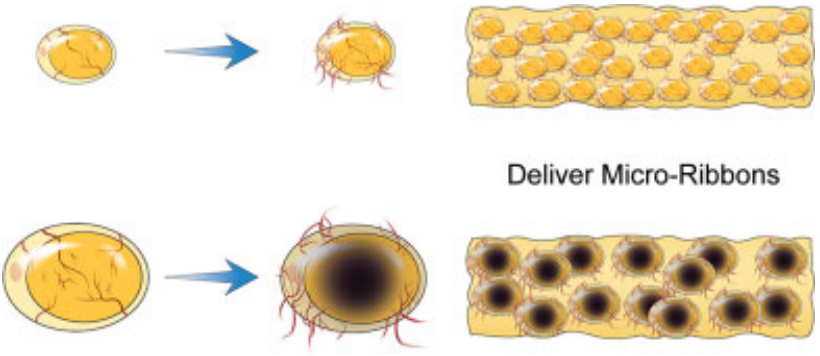

Fig. 1 Only microdroplets with radii less than $1.6 \mathrm{~mm}$ will completely revascularize and survive.

When transferred as an avascular graft, three cellular zones are formed. The most peripheral zone, containing adipocytes that survive the resultant hypoxia; a regenerative zone, directly underneath containing ADSCs that revascularize and regenerate into new adipocytes; and a central necrotic zone where no cells survive ( - Fig. 1 ). ${ }^{31-33}$ Since oxygen diffusion is the rate-limiting step, only microdroplets with a regenerative zone of maximum depth of $1.6 \mathrm{~mm}$ are able to fully survive the transfer. ${ }^{33}$ Therefore, to ensure minimal necrosis, large graft volumes must be sprinkled in a three-dimensional (3D) fashion to create microdroplets that do not coalesce (-Fig. 2 ).

To understand how much fat can be grafted successfully into a given recipient site, one should think of a fat graft in the same way we think of the stoichiometry of a chemical reaction, as explained by Khouri et al. ${ }^{34}$ To achieve a revascularized graft-recipient complex (GR), a fat droplet (G) must combine with a capillary receptor site $(R)$. Therefore, a certain amount of recipient sites $(R)$ can only accommodate a limited amount of graft $(G)$ without resulting in graft necrosis ( - Fig. 3 ). While fat grafting success is frequently measured as graft survival

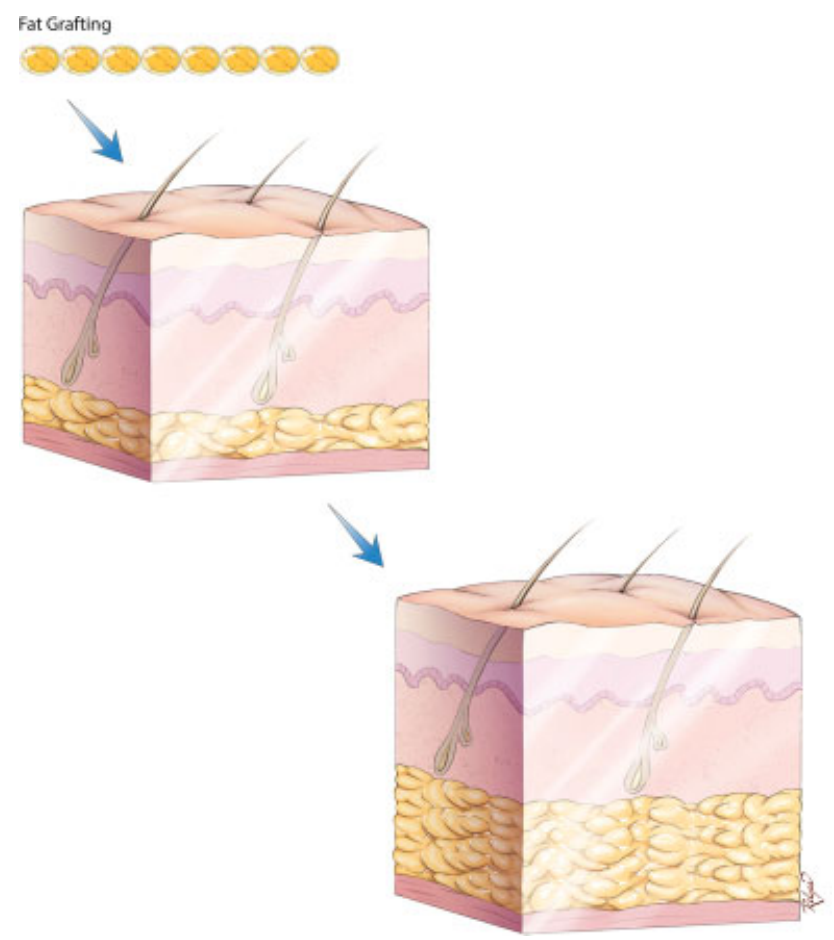

Fig. 2 Sprinkle micrograft delivery is performed to maximize graft-torecipient interface. percentage, this measure tells us nothing about the actual increase in volume. For example, in a volume augmentation procedure, this measure provides no information on the volume increase from the original volume at the recipient site.

\section{Fat Grafting Technique}

The process of fat grafting can be arbitrarily divided into five main components-(1) donor site selection, (2) graft harvesting, (3) graft processing, (4) recipient site preparation, and (5) graft delivery. Based on the volume harvested, fat grafting can also be classified into three categories-small volume $(<100 \mathrm{~mL})$, typically for facial rejuvenation or regenerative purposes; large volume (100-200 $\mathrm{mL})$, primarily for breast and body contouring; or mega volume ( $>300 \mathrm{~mL}$ ), mainly for gluteal augmentation, breast augmentation, or breast reconstruction.

\section{Donor Site}

When it comes to choosing the donor site, several body areas that uniformly have abundant fat are suitable for harvesting. A comparison was done by Li et al on fat grafts harvested from six women using different donor sites including the flanks, upper and lower abdomen, and lateral and inner thigh. Their results demonstrated no significant differences among the donor sites in regards to weight, volume, or histological features (including fibrosis and neovascularization), and concluded that factors such as accessibility and patient preference should be considered for donor site selection. ${ }^{35}$ As a general rule, donor sites that improves body contour are preferred by patients and are easily accessible by surgeons.

\section{Recipient Site}

Determining the capacity of the recipient site is key when planning the amount of graft to be harvested. Recipient capacity is a function of volume and mechanical compliance. This is commonly estimated by the palm-and-pinch technique. Laxity and thickness are approximated by pinching the tissue, whereas the palm estimates the surface area (the average palm size of a man is $200 \mathrm{~cm}^{2}$ ).

Recognizing the grafting capacity of a recipient site is vital, and attempting to graft more is counterproductive. The surgeon must always keep in mind not to graft beyond what the recipient site can physiologically stretch to accommodate. However, the key for a successful large volume autologous fat transfer is external volume expansion. Studies have shown that it can induce adipogenesis, enhance tissue vascularity, and increase recipient capacity and mechanical compliance, thereby priming the recipient site for a large volume fat transfer. ${ }^{36-40}$

\section{Harvesting, Processing, and Delivery}

After selecting the donor site and optimizing the recipient site, determining the harvesting approach becomes the next step. Direct excision, manual aspiration, and liposuction are among the techniques described in the literature. ${ }^{41}$ For liposuction or manual aspiration to be performed, negative pressures are required. Despite the heterogeneity between the negative pressure values suggested by different authors, it is well 


\section{Stoichiometry of Graft - Recipient Interaction}

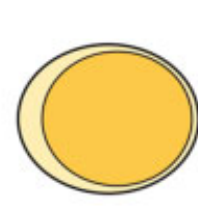

Graft (G)

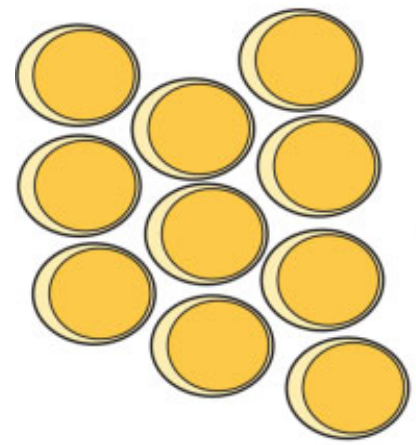

10 Grafts (G)

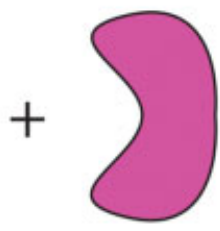

Recipient (R)

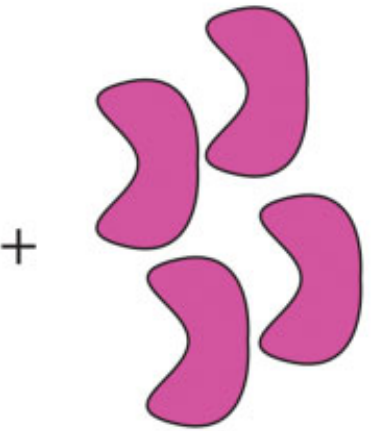

4 Recipients (R)
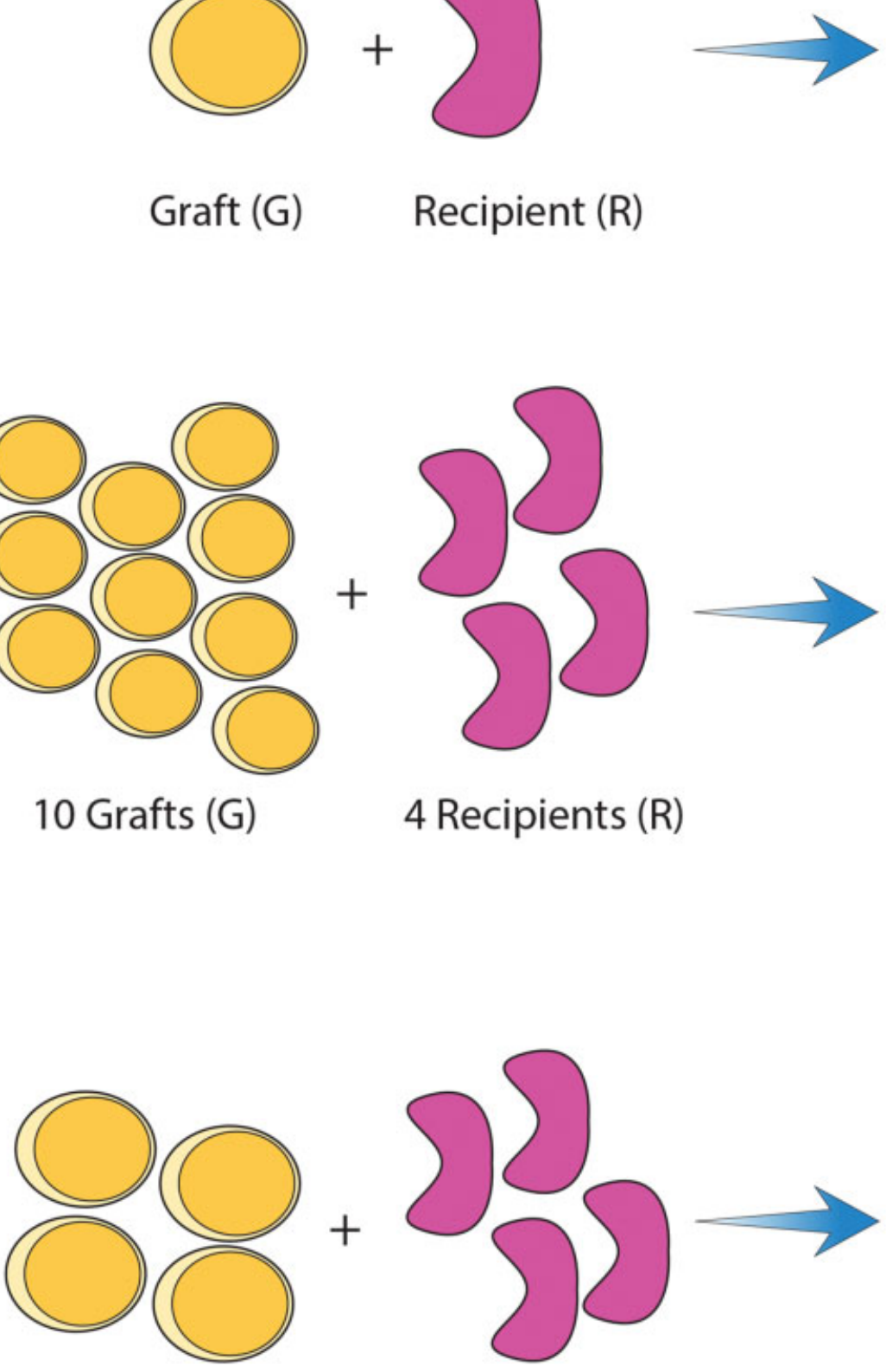

4 Recipients ( $R$ )

4 Grafts (G)

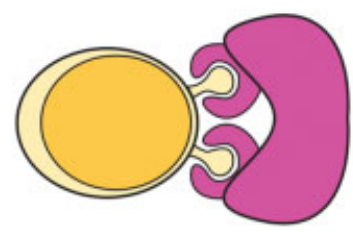

Surviving Graft (RG)

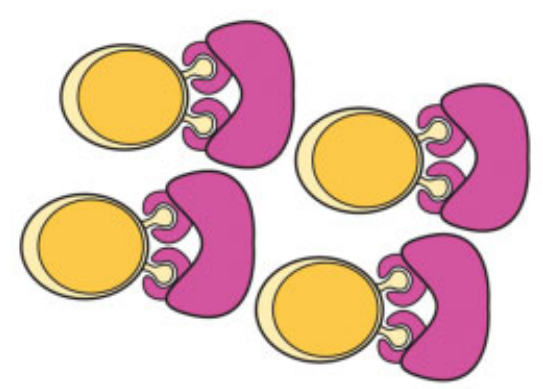

\section{Surviving Grafts (RG) \\ Maximum Graft Survival \& Maximum Augmentation}

Fig. 3 Stoichiometry of fat grafting principle as described by Khory et al in $2017 .{ }^{34}$ To create a surviving graft-recipient complex, a unit graft (G) has to interact with a capillary recipient site ( $R$ ). If only four recipient sites (4R) are available, adding $10 \mathrm{grafts}(10 \mathrm{G})$ will at best result in four surviving grafts (4RG) and six necrotic grafts, with $40 \%$ graft survival rate. By carefully adding the maximum amount of grafts a recipient site can tolerate, the procedure will yield $100 \%$ graft survival.

accepted that low vacuum pressure is less traumatic and enhances graft viability. ${ }^{42}$

Based on the volume of the solution injected into the fat donor site, several liposuction techniques can be identified including the dry technique, the wet technique, the superwet technique, and the tumescent technique. The tumescent technique, first introduced by Klein in 1987, uses large amounts of a very dilute solution, usually lidocaine with epinephrine, that 
is injected into the subcutaneous fat compartments until a swollen state (tumescence) and complete local anesthesia (tumescent local anesthesia) are achieved. ${ }^{43}$ The tumescent solution has to be injected 45 minutes before harvesting to ensure adequate hydrodissection. The resultant ratio of infiltrate volume to total aspirate volume is typically 2 to $3: 1 \mathrm{~L}$. This technique is considered to be the safest method of fat removal as associated blood loss is around $1 \%$ of the aspirated volume and general anesthesia is not required. ${ }^{41}$

Proper graft delivery is an extremely important factor that is often underappreciated in the literature. An even distribution of the fat graft at the recipient site is the key for a successful injection. A "blunt" tip smaller-gauge cannula is generally used for reinjecting the graft. The surgeon should inject the fat gently and slowly to avoid injuries to underlying structures, reduce shear stress, and increase graft viability. Multiple passes should be performed while depositing small amounts of fat with each pass at a rate of almost $<0.1 \mathrm{~mm} / \mathrm{cm}$. This technique limits fat clumping and eventual necrosis of the graft. ${ }^{34}$

\section{Clinical Applications}

\section{Breast Applications}

Ever since the concept of fat grafting to the breast was first introduced in 1895 by Czerny, multiple breast-related applications were described. ${ }^{44}$ The technique, however, was not without controversy as many feared its potential interference with breast cancer screening. In 2007, Rigotti et al published a study reporting no increase in breast cancer recurrence rate in women who underwent breast reconstruction using fat grafting. ${ }^{28}$ Additional studies have also proven that radiographic follow-up of fat grafted breasts does not preclude accurate breast cancer screening. ${ }^{45,46}$ It was not until 2009 when the Fat Grafting Task Force of the American Society of Plastic Surgeons released a study describing fat grafting along with a statement saying "[f]at grafting may be considered for breast augmentation and correction of defects associated with medical conditions and previous breast surgeries; however, results are dependent on technique and surgeon expertise."

\section{Augmentation Mammoplasty}

When using fat for augmentation, one must always remember that fatty tissue is not an expander. The capacity of the recipient site must be increased prior to fat grafting in order for the site to be augmented, particularly for those with very small breasts or tight skin envelopes. Using external volume expansion prior to grafting is often advocated with consistent and remarkable results. ${ }^{47}$ In recent years, fat grafting for breast augmentation have shown great aesthetic outcomes with high patient satisfaction in regards to size, shape, and texture of the breast mound. Li et al, Zheng et al, and Coleman and Saboeiro all reported autologous fat graft as an effective approach for cosmetic breast augmentation. ${ }^{48-50}$

\section{Breast Reconstruction}

Using fat grafting for breast reconstruction is more challenging than primary augmentation due to the accompanied loss of compliance and vascularity. In addition, the mastectomy scar and radiation-induced damage result in an environment that is unfavorable for graft survival. Nonetheless, breast reconstruction with autologous fat transfer offers the advantage of having a soft, sensate, and a naturally appearing breast mound. The number of fat grafting sessions required to reconstruct a mastectomy often depends on the history of breast radiation and the degree of scar tissue from previous failed reconstructions. Nonirradiated mastectomy with minimal scarring often requires three consecutive grafting sessions, each three months apart. ${ }^{34}$ On the other hand, an irradiated breast generally requires two further sessions, and additional scarring from prior failed reconstructions might require even more. ${ }^{34}$

Primary reconstruction of the breast is not the only application of autologous fat grafting following a mastectomy. Secondary contour deformities of the reconstructed breast are common and often pose a frequent therapeutic challenge to the reconstructive surgeon. ${ }^{51}$ Fat grafting offers a simple solution to restore the normal contour of the breast following reconstruction. In fact, lipofilling became the workhorse for the correction of defects and asymmetry following breast cancer surgery. ${ }^{52,53}$ Another important applications are improving soft tissue coverage following breast implant placement as well as volume augmentation after autologous flap reconstruction. ${ }^{52,53}$

Multiple reasons can lead the patient or the surgeon to the decision of removing an implant. Despite being a frequently performed plastic surgery procedure, implant-based breast reconstruction can be associated with considerable revision rates. ${ }^{54}$ Several investigators have advocated for autologous fat transfer as an alternative or an adjunct to a second implantation. Replacing implant volume with autologous fat can be the simplest solution to several of the implant problems. The resultant cavity after implant removal is the ideal recipient for fat transfer, particularly when implant explanation and fat grafting are performed simultaneously during the same procedure. $^{34}$ Immediately after removal, the tissues are lax and maximally compliant to accommodate the grafted fat. However, over time, should the cavity remain empty, the excess skin folds over and retracts creating deep wrinkles. ${ }^{34}$

\section{Gluteal Augmentation}

Gluteal augmentation with autologous fat transfer is an increasingly popular well-established procedure with the ability to transform the entire body silhouette of the patient. ${ }^{55}$ There are several advantages to the use of autologous fat grafting for buttock augmentation. Fat transfer allows focused augmentation and contouring of the gluteal and thigh region in addition to reduction of adjacent body regions, thereby resulting in improvement of the overall body aesthetics. ${ }^{56}$ The combination of augmentation adjacent to reduction achieves patients' goals for "S" curvilinear body contour in ways that cannot be accomplished with any other technique. Furthermore, the use of autologous fatty tissue avoids implant-associated complications such as seroma, capsular contracture, migration, or implant exposure. ${ }^{57}$

Several complications are reported in the literature including infection, abscess formation, contour irregularities, sciatic 
nerve injury, and rarely fat emboli and death. ${ }^{58,59}$ Fatal fat embolism can potentially occur from inadvertent injections in the gluteal vein plexus. Despite these known complications, with meticulous technique as well as proper patient selection and perioperative protocols, the procedure can be safely performed with consistently excellent short- and long-term results and high patient satisfaction. ${ }^{56}$

\section{Facial Contouring}

Several fillers have been proposed to address the soft tissue volume loss in facial aging. However, the recognition that most of the volume loss is the result of fatty tissue atrophy has driven surgeons to consider autologous fat transfer as a replacement in facial rejuvenation procedures. Fat provides a readily available and appealing tissue for facial transplantation, despite having some limitations in the predictability of volume maintenance. In most studies, the overall survival rate following fat grafting has been reported at around 50\%, which is not considered an ideal percentage. Various grafting and injection protocols have been proposed to increase the viability and the survival of the graft. ${ }^{60}$ In 2007, Kaufman et al described several modifications that can potentially improve graft survival and volume maintenance including "nontraumatic" blunt cannula technique and immediate injection of small amounts in multiple passes. ${ }^{61}$ Despite these limitations, reported patient and physician satisfaction regarding the final cosmetic outcomes of the procedure remain high. 62

Facial rejuvenation requires both a facelift procedure and lipofilling. When it comes to facial fat transplant, a thin layer of strategically placed compacted centrifuged fat can result in excellent graft-to-recipient ratio with high graft survival. In a recent systematic review of 18 articles investigating autologous fat grafting for facial rejuvenation, the number of required sessions varied between the studies, ranging from 1 to 4 sessions with a mean interval of 4.25 months. ${ }^{63}$ Furthermore, the subcutaneous space was the primary site of injection with additional injections most often performed above or just beneath the superficial muscular aponeurotic system (SMAS). In regards to volumetric analysis, the authors found it impractical to compare the degree of volume retention between the studies as the face consists of multiple anatomical units greatly varying in important features such as density. Moreover, great heterogeneity was found between the studies in regard to injection site and volumetric assessment; therefore, pooling of volume data was not possible. Patient satisfaction was reported around $81 \%$, while surgeons reported a good cosmetic outcome in $89 \%$ of the cohort.

\section{Hand Rejuvenation}

The appearance of the hands has always been an indicator of someone's true age. Such age-related changes occur due to both intrinsic and extrinsic factors. With advanced age collagen depletion and dehydration gradually lead to tissue atrophy and loss of the subcutaneous fullness in the hands. In turn, these changes result in skin wrinkling and visibility of the extensor tendons and subcutaneous veins on the dorsum of the hand. ${ }^{64}$ Extrinsic factors, such as photoaging, can lead to irregular pigmentations including actinic keratosis, seborrhoeic keratosis, solar lentigines, and solar purpura. ${ }^{64}$

The procedure is performed under local anesthesia using blunt cannulas to minimize the risk of dorsal vein perforation. Generally, 10 to $30 \mathrm{~mL}$ of fat is injected to give the hand a slightly overfilled appearance. Furthermore, injecting a small volume at the base of the fingers provides a more uniform appearance to the entire hand. ${ }^{64}$ In addition to acting as a filler for volume augmentation, the regenerative potential improves the quality of the soft tissue and the skin making autologous fat transfer the ideal approach for hand rejuvenation.

\section{Fibrosis and Scars}

The cicatrix-to-matrix concept was first described by Khouri et al where the authors explained how autologous fat transfer can turn tight fibrous tissue into loose recipient matrix. ${ }^{65}$ The application of this new approach provides a valuable regenerative alternative to flap surgery in the treatment of scar contractures and fibrous tissue.

\section{Scar Contractures}

Percutaneous aponeurotomy and lipofilling (PALF) is a fat grafting technique that relies primarily on maximizing the recipient site's capacity to accept and support the graft. The subcutaneous aponeurosis is the restrictive underlying scar or the subcutaneous fascia that limits tissue advancement and primary closure at defect sites. By percutaneously meshing the restrictive scar and expanding the resultant microcavities with fat grafting, the cicatrix can be transformed into fat-filled matrix. For proper 3D release, the expansion must be made via staggered nicks in multiple planes with different directions wherever restrictive fibers prevent expansion, thus increasing the surface area and allowing further tissue advancement. This generates a scaffold of small pockets or gaps, interspersed with thin connective bands of the original scar, that are ideal for seeding with autologous fat to regenerate the defect. The loosened scar becomes softer and closer to the surrounding fatty tissue. To correct volume deficiencies, the process is repeated a few months later leading to substantial volume gain and the potential to eliminate the scar completely. Percutaneous mesh expansion should not be confused with relaxing incisions, which create large gaps where the grafts may collect in large deposits and die due to inadequate graft-recipient interface.

The procedure has been performed on scars and defects located in several body parts including the trunk, breasts, extremities, and face. ${ }^{65}$ In addition, multiple pathologies were successfully treated such as burn scar contractures, breast agenesis, posttraumatic scars, and Dupuytren's contracture. $^{34}$ When performing PALF to treat Dupuytren's contracture, it is important to remember that the key is strong digital extension when releasing the cord, to avoid damage to the neurovascular structures. ${ }^{66}$ Forceful extension tenses the cords before the neurovascular structures become tight, thereby selectively cutting the restrictive fibers with the needle during the expansion. ${ }^{66}$ Moreover, 
studies have shown that abdominal adipose tissue has an inhibitory effect on Dupuytren's fibroblasts. ${ }^{67}$

\section{Radiation Defects}

Radiation therapy results in the destruction of both cancer cells and ADSCs alike, leaving behind a tissue with poor regenerative capabilities and a hostile environment for engraftment. While the first round of fat grafting results in poor survival, subsequent rounds are met with better graft take due to the abundance of ADSCs in the liposuctioned fat. With each fat grafting session, the content of the tissue becomes richer and richer in stem cells and eventually more and more approaching the normal tissue in both properties and cellular content. The procedure is best performed immediately after the radiation before the fibrosis sets in.

\section{Future Applications}

The regenerative potential and the relative ease by which ADSCs are obtained have encouraged a large number of experiments to study their reconstructive potential. Cultured ADSCs have shown massive differentiation potential in vitro. Besides the logical mesenchymal tissues such as bone, cartilage, and adipose tissue, ADSCs have also shown paracrine and differentiation potential in skin tissue engineering and nerve reconstruction. ${ }^{68,69}$ The full therapeutic potential of such differentiation capabilities remains an area of debate. While some researchers suggest that ADSCs exert their therapeutic potential through differentiation into a specific cell type in target tissue, others contradict this suggestion by arguing that despite the phenotypic differentiation, the newly formed target cells lack full functionality. ${ }^{70}$

Studies focusing on the use of ADSCs in tissue engineering have also been reported in the literature. Many aspects of the procedure still need to be investigated and established such as the biocompatible scaffold, the seeding process, vascularization, and the use of ADSCs (differentiated or undifferentiated, alone or in combination with other cell types). ${ }^{71,72}$ The main dilemma is achieving vascularization after in vivo implantation. Multiple approaches to form a viable, organized vascular network have been proposed such as incorporating biomaterials with favorable angiogenic properties, using mechanical stimulation, as well as using 3D cell printing.

Others researchers have taken a different approach and focused on the therapeutic potential that can be exploited from ADSC's paracrine activity. Several studies confirmed the ability of ADSCs to promote tissue regeneration through their secretion of a multitude of cytokines and growth factors, particularly in hypoxic conditions. ${ }^{73}$ These include angiogenic cytokines such as vascular endothelial growth factor (VEGF), fibroblast growth factor 2 (FGF-2), and basic fibroblast growth factor (b-FGF) as well as hematopoietic cytokines such as granulocyte-colony stimulating factor (G-CSF) and granulocyte/macrophage-colony stimulating factor $(\mathrm{GM}-\mathrm{CSF}){ }^{74}$ According to the clinical trials database, almost 112 clinical studies are currently being performed using ADSCs, including diabetic foot, facial rejuvenatoin, Crohn's disease, and spinal cord injury. $^{75}$

\section{Complications}

Donor-site complications are generally minimal and are related to the liposuction technique. Possible complications include bruising, paresthesia, and damage to the underlying structures.

When fat grafting the breast, potential complications include fat necrosis, oil cyst formation, and calcification. In a systematic review performed by Agha et al, the complications rate in 2,832 fat-grafted breasts was found to be $7.3 \%$. Fat necrosis accounted for $62 \%$ of all complications and was reported in 17 of the 24 studies. $^{76}$ Such adverse events can occur at higher rates if large volumes are injected without adequate distribution or if fat is injected into poorly vascularized regions. In addition, fat necrosis can result in palpable masses that are indistinguishable on examination from local recurrence in breast cancer patients resulting in additional imaging and needle biopsies. ${ }^{50}$

The face is an anatomically complex area of the body, compacted with a multitude of important structures. Most complications when transplanting fat into the face are due to injecting fat in critical areas such as the nasolabial folds. Upon injecting the grafts, increase in local pressure can result in reflux of the fat into the ophthalmic artery, resulting in blindness or the internal carotid artery causing a stroke. ${ }^{77}$ Multiple steps can be undertaken to minimize the risk of such devastating complications starting by ensuring the absence of blood reflux prior to the injection, injecting slowly and at a low pressure, and using the blunt-tip cannula. ${ }^{77}$

\section{Limitations}

Despite the demonstrated benefits and therapeutic potential of adipose tissue in a variety of application, its limitations have to be acknowledged and addressed. Perhaps the most important limitation is the oncological risk when fat grafting the breast. Even though many studies have shown no increased risk, this remains the most expressed concern among surgeons and patients.

One of the fundamental limitations is that the amount of tissue transfer is strictly limited by the amount of fatty tissue available in the patient. Ensuring fat cells viability is crucial, and while every step in the process of fat grafting is important, the chances of survival are higher when the graft is less manipulated and delayed after harvesting. The lack of standardization in harvesting and injection protocols, combined with the unpredictability of the resorption rate, pose a significant limitation for graft retention. Furthermore, information regarding long-term viability of the transferred fat is still unavailable, making long-term results unpredictable. Another important concern includes lack of a consistent evidence regarding revisions, use of additional interventions following resorption, and the ever-existing potential for future injections. 
Comparisons between methods tend to vary broadly according to the outcome measured, thereby limiting the ability to determine the most efficient method for fat grafting. Moreover, the absence of a standard method to evaluate the viability or the degree of volume augmentation of the fat graft remains another obstacle in the way of achieving a universally agreed upon fat grafting protocol.

\section{Conclusion}

With its filling and regenerative properties, autologous fat transfer provides a reliable minimally invasive procedure for many reconstructive and aesthetic procedures. With the principles of fat grafting well described in the literature, establishing best-practice guidelines for fat grafting applications should become a priority moving forward. A very promising area of experimental research in adipose reconstructive medicine is developing, and more significant applications will soon become available.

\section{Conflict of Interest}

None declared.

\section{References}

1 Neuber F. Fettransplantation. Bericht über die Verhandlungen der deutschen Gesellscaft für Chirurgie. Zentralbl Chir 1893;22:66

2 Coleman SR. Facial recontouring with lipostructure. Clin Plast Surg 1997;24(02):347-367

3 Coleman SR, Katzel EB. Fat grafting for facial filling and regeneration. Clin Plast Surg 2015;42(03):289-300, vii.

4 Coleman SR. Structural fat grafts: the ideal filler? Clin Plast Surg 2001;28(01):111-119

5 Ergün SS, Baygöl EG, Kayan RB, Kuzu İM, Akman O. Correction of brassiere strap grooves with fat injections. Aesthet Surg J 2015;35 (05):561-564

6 Cárdenas JC, Carvajal J. Refinement of rhinoplasty with lipoinjection. Aesthetic Plast Surg 2007;31(05):501-505

7 Guyuron B, Majzoub RK. Facial augmentation with core fat graft: a preliminary report. Plast Reconstr Surg 2007;120(01):295-302

8 Butterwick KJ. Lipoaugmentation for aging hands: a comparison of the longevity and aesthetic results of centrifuged versus noncentrifuged fat. Dermatol Surg 2002;28(11):987-991

9 Cantarella G, Mazzola RF, Gaffuri M, et al. Structural fat grafting to improve outcomes of vocal folds' fat augmentation: long-term results. Otolaryngol Head Neck Surg 2018;158(01):135-143

10 Al-Hayder S, Gramkow C, Trojahn Kølle SF. Use of autologous fat grafting for the correction of burn scar contracture in the hand: a case report. Case Reports Plast Surg Hand Surg 2017;4(01):81-83

11 Klinger M, Lisa A, Klinger F, et al. Regenerative approach to scars, ulcers and related problems with fat grafting. Clin Plast Surg 2015;42(03):345-352, viii

12 Jianhui Z, Chenggang Y, Binglun L, et al. Autologous fat graft and bone marrow-derived mesenchymal stem cells assisted fat graft for treatment of Parry-Romberg syndrome. Ann Plast Surg 2014; 73(Suppl 1):S99-S103

13 Balaji SM. Subdermal fat grafting for Parry-Romberg syndrome. Ann Maxillofac Surg 2014;4(01):55-59

14 Yang H, Lee H. Successful use of squeezed-fat grafts to correct a breast affected by Poland syndrome. Aesthetic Plast Surg 2011;35 (03):418-425

15 Tuncel U, Kurt A, Gumus M, Aydogdu O, Güzel N, Demir O. Preliminary results with non-centrifuged autologous fat graft and percutaneous aponeurotomy for treating Dupuytren's disease. Hand Surg Rehabil 2017;36(05):350-354

16 Strong AL, Cederna PS, Rubin JP, Coleman SR, Levi B. The current state of fat grafting: a review of harvesting, processing, and injection techniques. Plast Reconstr Surg 2015;136(04):897-912

17 Laloze J, Varin A, Bertheuil N, Grolleau JL, Vaysse C, Chaput B. Cellassisted lipotransfer: current concepts. Ann Chir Plast Esthet 2017;62(06):609-616

18 Bourin P, Bunnell BA, Casteilla L, et al. Stromal cells from the adipose tissue-derived stromal vascular fraction and culture expanded adipose tissue-derived stromal/stem cells: a joint statement of the International Federation for Adipose Therapeutics and Science (IFATS) and the International Society for Cellular Therapy (ISCT). Cytotherapy 2013;15(06):641-648

19 Tocco I, Widgerow AD, Lalezari S, Banyard D, Shaterian A, Evans GR. Lipotransfer: the potential from bench to bedside. Ann Plast Surg 2014;72(05):599-609

20 Laloze J, Varin A, Gilhodes J, et al. Cell-assisted lipotransfer: friend or foe in fat grafting? Systematic review and meta-analysis. J Tissue Eng Regen Med 2018;12(02):e1237-e1250

21 Matsumoto D, Sato K, Gonda K, et al. Cell-assisted lipotransfer: supportive use of human adipose-derived cells for soft tissue augmentation with lipoinjection. Tissue Eng 2006;12(12): 3375-3382

22 Yoshimura K. Cell-assisted lipotransfer for breast augmentation: grafting of progenitor-enriched fat tissue. In: Shiffman M, ed. Autologous Fat Transfer. Berlin, Germany: Springer; 2010:261-271

23 Rosen ED, MacDougald OA. Adipocyte differentiation from the inside out. Nat Rev Mol Cell Biol 2006;7(12):885-896

24 Rubina K, Kalinina N, Efimenko A, et al. Adipose stromal cells stimulate angiogenesis via promoting progenitor cell differentiation, secretion of angiogenic factors, and enhancing vessel maturation. Tissue Eng Part A 2009;15(08):2039-2050

25 Walocko FM, Khouri RK Jr, Urbanchek MG, Levi B, Cederna PS. The potential roles for adipose tissue in peripheral nerve regeneration. Microsurgery 2016;36(01):81-88

26 Charles-de-Sá L, Gontijo-de-Amorim NF, Maeda Takiya C, et al. Antiaging treatment of the facial skin by fat graft and adiposederived stem cells. Plast Reconstr Surg 2015;135(04):999-1009

27 Yun IS, Jeon YR, Lee WJ, et al. Effect of human adipose derived stem cells on scar formation and remodeling in a pig model: a pilot study. Dermatol Surg 2012;38(10):1678-1688

28 Rigotti G, Marchi A, Galiè M, et al. Clinical treatment of radiotherapy tissue damage by lipoaspirate transplant: a healing process mediated by adipose-derived adult stem cells. Plast Reconstr Surg 2007;119(05):1409-1422, discussion 1423-1424

29 Wu L, Cai X, Zhang S, Karperien M, Lin Y. Regeneration of articular cartilage by adipose tissue derived mesenchymal stem cells: perspectives from stem cell biology and molecular medicine. J Cell Physiol 2013;228(05):938-944

30 Lopez-Santalla M, Menta R, Mancheño-Corvo P, et al. Adiposederived mesenchymal stromal cells modulate experimental autoimmune arthritis by inducing an early regulatory innate cell signature. Immun Inflamm Dis 2016;4(02):213-224

31 Eto $\mathrm{H}$, Kato $\mathrm{H}$, Suga $\mathrm{H}$, et al. The fate of adipocytes after nonvascularized fat grafting: evidence of early death and replacement of adipocytes. Plast Reconstr Surg 2012;129(05):1081-1092

32 Kato $\mathrm{H}$, Mineda K, Eto $\mathrm{H}$, et al. Degeneration, regeneration, and cicatrization after fat grafting: dynamic total tissue remodeling during the first 3 months. Plast Reconstr Surg 2014;133(03):303e-313e

33 Khouri RK Jr, Khouri RE, Lujan-Hernandez JR, Khouri KR, Lancerotto L, Orgill DP. Diffusion and perfusion: the keys to fat grafting. Plast Reconstr Surg Glob Open 2014;2(09):e220

34 Khouri RK Jr, Khouri RK. Current clinical applications of fat grafting. Plast Reconstr Surg 2017;140(03):466e-486e

$35 \mathrm{Li} \mathrm{K}$, Gao J, Zhang Z, et al. Selection of donor site for fat grafting and cell isolation. Aesthetic Plast Surg 2013;37(01):153-158 
36 Pietramaggiori G, Liu P, Scherer SS, et al. Tensile forces stimulate vascular remodeling and epidermal cell proliferation in living skin. Ann Surg 2007;246(05):896-902

37 Chin MS, Ogawa R, Lancerotto L, et al. In vivo acceleration of skin growth using a servo-controlled stretching device. Tissue Eng Part C Methods 2010;16(03):397-405

38 Heit YI, Lancerotto L, Mesteri I, et al. External volume expansion increases subcutaneous thickness, cell proliferation, and vascular remodeling in a murine model. Plast Reconstr Surg 2012;130(03): 541-547

39 Khouri RK, Schlenz I, Murphy BJ, Baker TJ. Nonsurgical breast enlargement using an external soft-tissue expansion system. Plast Reconstr Surg 2000;105(07):2500-2512, discussion 25132514

40 Myung Y, Kwon H, Pak C, Lee H, Jeong JH, Heo CY. Radiographic evaluation of vessel count and density with quantitative magnetic resonance imaging during external breast expansion in Asian women: a prospective clinical trial. J Plast Reconstr Aesthet Surg 2016;69(12):1588-1597

41 Halk AB, Habbema L, Genders RE, Hanke CW. Safety studies in the field of liposuction: a systematic review. Dermatol Surg 2019;45(02): 171-182

42 Fontes T, Brandão I, Negrão R, Martins MJ, Monteiro R. Autologous fat grafting: harvesting techniques. Ann Med Surg (Lond) 2018; 36:212-218 Web

43 Klein JA. Anesthesia for liposuction in dermatologic surgery. J Dermatol Surg Oncol 1988;14(10):1124-1132

44 Czerny V. Plastischer erzats de brustdruse durch ein lipom. Zentralbl Chir 1895;27:72

45 Rigotti G, Marchi A, Stringhini P, et al. Determining the oncological risk of autologous lipoaspirate grafting for post-mastectomy breast reconstruction. Aesthetic Plast Surg 2010;34(04):475-480

46 Veber M, Tourasse C, Toussoun G, Moutran M, Mojallal A, Delay E. Radiographic findings after breast augmentation by autologous fat transfer. Plast Reconstr Surg 2011;127(03):1289-1299

47 Khouri R, Del Vecchio D. Breast reconstruction and augmentation using pre-expansion and autologous fat transplantation. Clin Plast Surg 2009;36(02):269-280, viii

48 Li FC, Chen B, Cheng L. Breast augmentation with autologous fat injection: a report of 105 cases. Ann Plast Surg 2014;73(Suppl 1): S37-S42

49 Zheng DN, Li QF, Lei $\mathrm{H}$, et al. Autologous fat grafting to the breast for cosmetic enhancement: experience in 66 patients with long-term follow up. J Plast Reconstr Aesthet Surg 2008;61(07):792-798

50 Coleman SR, Saboeiro AP. Fat grafting to the breast revisited: safety and efficacy. Plast Reconstr Surg 2007;119(03):775-785, discussion 786-787

51 Cigna E, Ribuffo D, Sorvillo V, et al. Secondary lipofilling after breast reconstruction with implants. Eur Rev Med Pharmacol Sci 2012;16(12):1729-1734

52 Hamza A, Lohsiriwat V, Rietjens M. Lipofilling in breast cancer surgery. Gland Surg 2013;2(01):7-14

53 Simonacci F, Bertozzi N, Grieco MP, Grignaffini E, Raposio E. Autologous fat transplantation for breast reconstruction: a literature review. Ann Med Surg (Lond) 2016;12:94-100

54 Blanchard R, Legault S, Lindsay WR. Vaginoplasty outcome in maleto-female transsexuals. J Sex Marital Ther 1987;13(04):265-275

55 Surgeons ASP. 2016 National Clearinghouse of Plastic Surgery Statistic Report. 2017https://www.plasticsurgery.org/news/plastic-surgery-statistics. Accessed February 17, 2017.

56 Ghavami A, Villanueva NL. Gluteal augmentation and contouring with autologous fat transfer: part I. Clin Plast Surg 2018;45(02):249-259

57 Mofid MM, Gonzalez R, de la Peña JA, Mendieta CG, Senderoff DM, Jorjani S. Buttock augmentation with silicone implants: a multicenter survey review of 2226 patients. Plast Reconstr Surg 2013; 131(04):897-901
58 Cardenas-Mejia A, Martínez JR, León D, Taylor JA, Gutierrez-Gomez C. Bilateral sciatic nerve axonotmesis after gluteal lipoaugmentation. Ann Plast Surg 2009;63(04):366-368

59 Cárdenas-Camarena L, Bayter JE, Aguirre-Serrano H, CuencaPardo J. Deaths caused by gluteal lipoinjection: what are we doing wrong? Plast Reconstr Surg 2015;136(01):58-66

60 Pu LLQ, Coleman SR, Cui X, Ferguson RE Jr, Vasconez HC. Autologous fat grafts harvested and refined by the Coleman technique: a comparative study. Plast Reconstr Surg 2008;122(03):932-937

61 Kaufman MR, Miller TA, Huang C, et al. Autologous fat transfer for facial recontouring: is there science behind the art? Plast Reconstr Surg 2007;119(07):2287-2296

62 Kaufman MR, Bradley JP, Dickinson B, et al. Autologous fat transfer national consensus survey: trends in techniques for harvest, preparation, and application, and perception of short- and long-term results. Plast Reconstr Surg 2007;119(01):323-331

63 Groen JW, Krastev TK, Hommes J, Wilschut JA, Ritt MJPF, van der Hulst RRJW. Autologous fat transfer for facial rejuvenation: a systematic review on technique, efficacy, and satisfaction. Plast Reconstr Surg Glob Open 2017;5(12):e1606

64 Hoang D, Orgel MI, Kulber DA. Hand rejuvenation: a comprehensive review of fat grafting. J Hand Surg Am 2016;41(05):639-644

65 Khouri RK, Smit JM, Cardoso E, et al. Percutaneous aponeurotomy and lipofilling: a regenerative alternative to flap reconstruction? Plast Reconstr Surg 2013;132(05):1280-1290

66 Hovius SE, Kan HJ, Verhoekx JS, Khouri RK. Percutaneous aponeurotomy and lipofilling (PALF): a regenerative approach to Dupuytren contracture. Clin Plast Surg 2015;42(03):375-381, ix

67 Verhoekx JS, Mudera V, Walbeehm ET, Hovius SE. Adipose-derived stem cells inhibit the contractile myofibroblast in Dupuytren's disease. Plast Reconstr Surg 2013;132(05):1139-1148

68 Shen CC, Yang YC, Liu BS. Peripheral nerve repair of transplanted undifferentiated adipose tissue-derived stem cells in a biodegradable reinforced nerve conduit. J Biomed Mater Res A 2012; 100(01):48-63

69 Chan RK, Zamora DO, Wrice NL, et al. Development of a vascularized skin construct using adipose-derived stem cells from debrided burned skin. Stem Cells Int 2012;2012:841203

70 Nygren JM, Jovinge S, Breitbach $\mathrm{M}$, et al. Bone marrow-derived hematopoietic cells generate cardiomyocytes at a low frequency through cell fusion, but not transdifferentiation. Nat Med 2004;10 (05):494-501

71 Hu F, Zhang X, Liu H, et al. Neuronally differentiated adiposederived stem cells and aligned PHBV nanofiber nerve scaffolds promote sciatic nerve regeneration. Biochem Biophys Res Commun 2017;489(02):171-178

72 Kim WS, Park BS, Sung JH, et al. Wound healing effect of adiposederived stem cells: a critical role of secretory factors on human dermal fibroblasts. J Dermatol Sci 2007;48(01):15-24

73 Chung HM, Won CH, Sung JH. Responses of adipose-derived stem cells during hypoxia: enhanced skin-regenerative potential. Expert Opin Biol Ther 2009;9(12):1499-1508

74 Najar M, Raicevic G, Boufker HI, et al. Mesenchymal stromal cells use PGE2 to modulate activation and proliferation of lymphocyte subsets: combined comparison of adipose tissue, Wharton's Jelly and bone marrow sources. Cell Immunol 2010;264(02):171-179

75 U.S. National Institutes of Health. ClinicalTrials.gov identifier: NCT02765126. Available at: http://clinicaltrials.gov/2016. Accessed February 22, 2019

76 Agha RA, Fowler AJ, Herlin C, Goodacre TE, Orgill DP. Use of autologous fat grafting for breast reconstruction: a systematic review with meta-analysis of oncological outcomes. J Plast Reconstr Aesthet Surg 2015;68(02):143-161

77 Park SH, Sun HJ, Choi KS. Sudden unilateral visual loss after autologous fat injection into the nasolabial fold. Clin Ophthalmol 2008;2(03):679-683 